\title{
Dorsal Metatarsal Vein
}

National Cancer Institute

\section{Source}

National Cancer Institute. Dorsal Metatarsal Vein. NCI Thesaurus. Code C52689.

The vessels carrying deoxygenated blood on the upper side of the foot that orig inate from the dorsal digital vein creating the dorsal venous arch. 